\title{
Prostate Synovial Sarcoma
}

National Cancer Institute

\section{Source}

National Cancer Institute. Prostate Synovial Sarcoma. NCI Thesaurus. Code C161034.

A rare synovial sarcoma that arises from the prostate gland. 